\section{NUMBER OF UK} ADULTS SEEKING BRACES IS RISING

New figures released by The British Orthodontic Society (BOS) to coincide with National Smile Month, reveal the number of adults seeking orthodontic treatment in the UK continues to rise.

This survey, conducted in March 2018 among BOS members, was designed to gather new data about orthodontics and patient choices in the UK compared to two years ago.

Asked if they were seeing an increase in private adult treatment, $80 \%$ said yes. This figure compares to $75 \%$ in 2016.

The survey showed that adult patients are most likely to be female and in the 26-40 age bracket. However, the number of men seeking treatment appears to be on the rise. Nineteen percent of the respondents to the survey estimate that half of their adult
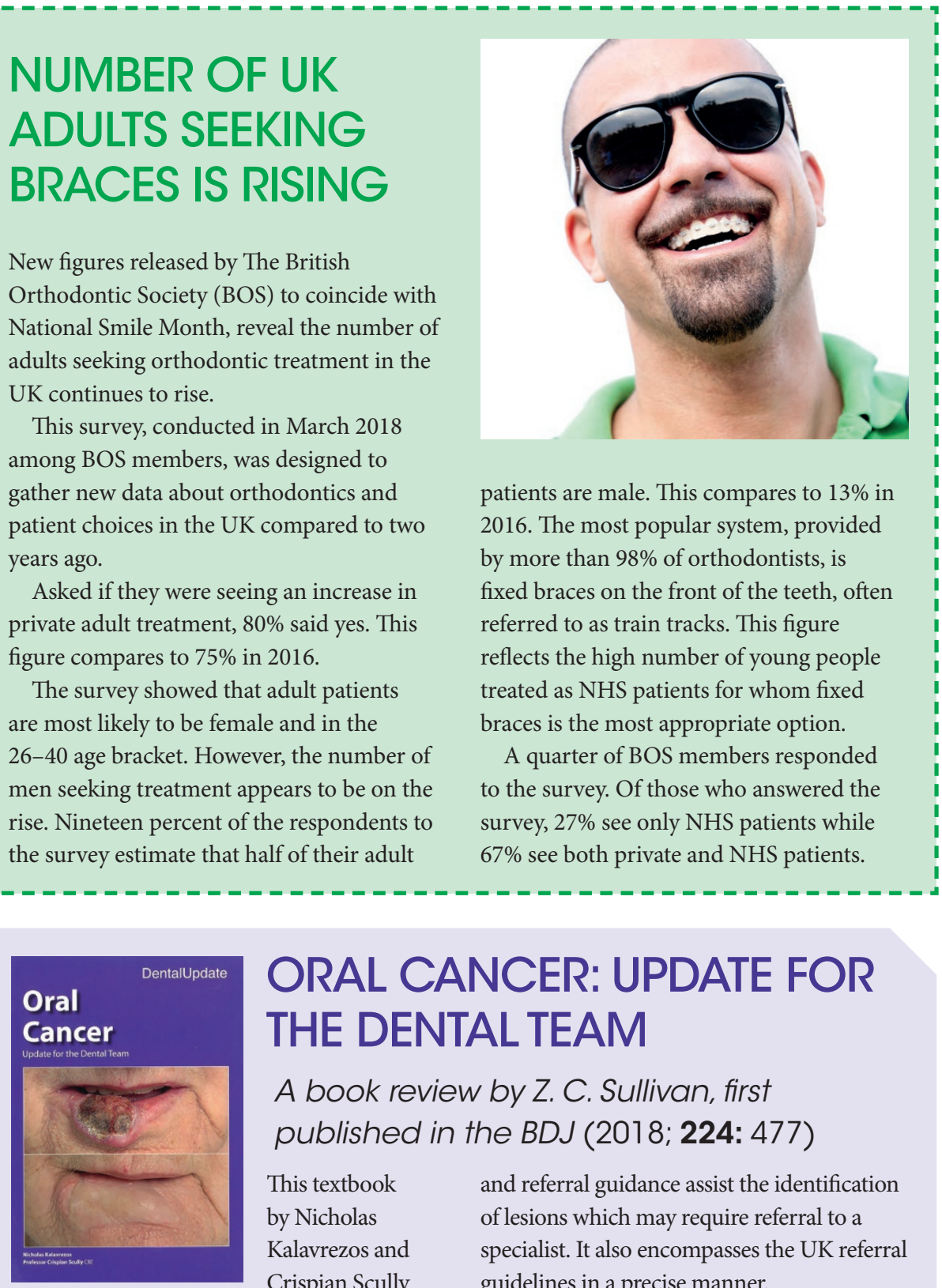

\section{ORAL CANCER: UPDATE FOR THE DENTAL TEAM}

\section{A book review by Z. C. Sullivan, first published in the BDJ (2018; 224: 477)}

This textbook by Nicholas Kalavrezos and Crispian Scully

covers the topic of oral cancer in a concise but detailed manner. The book certainly achieves its aim: to update the dental team, enhancing their knowledge on the many aspects of care and management that oral cancer encompasses. The chapters covering the risk factors for oral cancer will help dental team members to advise and aid patients in the cessation of habits which may prove detrimental to their oral and general health.

The layout of this book provides the reader with the necessary information in a logical manner. The opening chapter introduces the pathogenesis of cancer by introducing the reader to the cellular, histological and molecular changes that occur in the disease process. This is followed by three detailed chapters on the risk factors of oral cancer, which will enrich all clinicians who aim to promote preventative advice. The chapters which cover 'potentially malignant disorders' and referral guidance assist the identification of lesions which may require referral to a specialist. It also encompasses the UK referral guidelines in a precise manner.

In the chapters that cover oral cancer treatment and the patient care team, the authors efficiently summarise the relevant information to convey the patient journey. Such chapters would be of interest to any dental team member, however, they would be most beneficial to any dental core trainee that was undertaking a post in maxillofacial surgery, in a unit that treats head and neck cancer. The radiotherapy and chemotherapy aspects of oral cancer are also introduced to the reader, along with relevant complications that may present to dental clinicians.

Overall, the book fulfils its purpose entirely in updating the dental team on oral cancer; however, I would say it goes beyond its suggested intention. I feel that the book is probably best suited to those pursuing a career in oral medicine but each member of the dental team has knowledge to gain from reading some or all of this text.

\section{Dates}

\section{for your cliany}

\section{National Dental Nursing Conference}

The 2018 National

Dental Nursing

Conference, to

be held at the

Blackpool Hilton

on 16 and 17

November, will

be opened by

the Deputy Chief

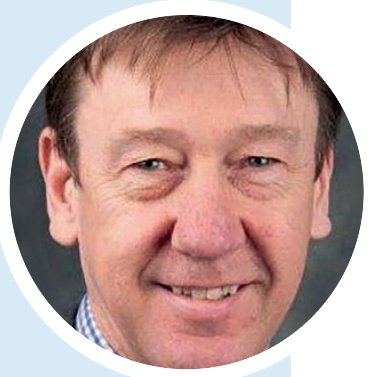

Dental Officer England, Eric Rooney

(pictured).

Mr Rooney will be the Keynote

Speaker at the Conference at the

Opening Ceremony on Friday

16 November, following the Meet the

President Welcome Lunch.

Other subjects on the conference programme include counterfeit equipment and materials, head and neck cancer, alcohol awareness, sepsis, communities of practice, dentistry for the disadvantaged and pride in practice.

Further information and a reservation form is available at www.badn.org.uk/ conference.

\section{The future is yours!}

The BSDHT's Oral Health Conference and Exhibition will be held on the 23 and 24 November 2018 at the Telford International Centre. It provides a fantastic opportunity for all dental hygienists, dental therapists and students to update their knowledge, gain verifiable CPD and meet likeminded professionals from across the country.

The theme of this year's event is 'The future is yours', focusing on professional development, empowerment and aspiration. It recognises that BSDHT members are clinical professionals with a huge and mostly untapped potential to develop as individuals and as part of a business.

To make sure you don't miss out, save the dates in your diary! 